\title{
Towards high-throughput molecular detection of Plasmodium: new approaches and molecular markers \\ Nicolas Steenkeste ${ }^{* \dagger 1}$, Sandra Incardona ${ }^{\dagger 1}$, Sophy Chy ${ }^{1}$, Linda Duval ${ }^{2}$, Marie- Thérèse Ekala ${ }^{3}$, Pharath Lim¹ ${ }^{1}$, Sean Hewitt ${ }^{4}$, Tho Sochantha ${ }^{5}$, Doung Socheat $^{5}$, Christophe Rogier ${ }^{6}$, Odile Mercereau-Puijalon ${ }^{3}$, Thierry Fandeur ${ }^{3}$ and Frédéric Ariey ${ }^{1}$
}

\begin{abstract}
Address: ${ }^{1}$ Institut Pasteur du Cambodge, Laboratoire d'Epidémiologie Moléculaire, BP 983, Phnom Penh, Cambodia, ${ }^{2}$ Institut Pasteur, Unité de Pathogénie Virale, Paris, France, ${ }^{3}$ Institut Pasteur, Unité d'Immunologie Moléculaire des Parasites, CNRS URA 2581, Paris, France, ${ }^{4}$ European Commission National Malaria Control Program, Phnom Penh, Cambodia, ${ }^{5}$ ational Center for Parasitology, Entomology and Malaria Control, Phnom Penh, Cambodia and ' Institut de Recherche Biomédicale des Armées - Antenne de Marseille/IMTSSA, Unité de Recherche en Biologie et Epidémiologie Parasitaires - Equipe «Moustiques et Maladies Emergentes » - UMR 6236 - URMITE, Marseille, France
\end{abstract}

Email: Nicolas Steenkeste* - nicolas.steenkeste@gmail.com; Sandra Incardona - sandra.incardona@yahoo.fr; Sophy Chy - chsophy@pasteurkh.org; Linda Duval - linduval@yahoo.fr; Marie-Thérèse Ekala - mtekala@yahoo.com; Pharath Lim - pharath@pasteur-kh.org; Sean Hewitt - sean.hewitt@vbdc-consulting.com; Tho Sochantha - sochanthat@cnm.gov.kh; Doung Socheat - socheatd@cnm.gov.kh; Christophe Rogier - christophe.rogier@wanadoo.fr; Odile Mercereau-Puijalon - odile.puijalon@pasteur.fr;

Thierry Fandeur - tfandeur@pasteur.fr; Frédéric Ariey - fariey@pasteur-kh.org

* Corresponding author †Equal contributors

Published: 29 April 2009

Malaria Journal 2009, 8:86 doi:10.1186/1475-2875-8-86

This article is available from: http://www.malariajournal.com/content/8/I/86

(C) 2009 Steenkeste et al; licensee BioMed Central Ltd.

This is an Open Access article distributed under the terms of the Creative Commons Attribution License (http://creativecommons.org/licenses/by/2.0), which permits unrestricted use, distribution, and reproduction in any medium, provided the original work is properly cited.

\begin{abstract}
Background: Several strategies are currently deployed in many countries in the tropics to strengthen malaria control toward malaria elimination. To measure the impact of any intervention, there is a need to detect malaria properly. Mostly, decisions still rely on microscopy diagnosis. But sensitive diagnosis tools enabling to deal with a large number of samples are needed. The molecular detection approach offers a much higher sensitivity, and the flexibility to be automated and upgraded.
\end{abstract}

Methods: Two new molecular methods were developed: dot18S, a Plasmodium-specific nested PCR based on the I $8 S$ rRNA gene followed by dot-blot detection of species by using species-specific probes and CYTB, a Plasmodium-specific nested PCR based on cytochrome $b$ gene followed by species detection using SNP analysis. The results were compared to those obtained with microscopic examination and the "standard" I 8S rRNA gene based nested PCR using species specific primers. 337 samples were diagnosed.

Results: Compared to the microscopy the three molecular methods were more sensitive, greatly increasing the estimated prevalence of Plasmodium infection, including P. malariae and P. ovale. A high rate of mixed infections was uncovered with about one third of the villagers infected with more than one malaria parasite species. Dot $18 \mathrm{~S}$ and CYTB sensitivity outranged the "standard" nested PCR method, CYTB being the most sensitive. As a consequence, compared to the "standard" nested PCR method for the detection of Plasmodium spp., the sensitivity of dot $18 \mathrm{~S}$ and CYTB was respectively $95.3 \%$ and $97.3 \%$. Consistent detection of Plasmodium spp. by the three molecular methods was obtained for $83 \%$ of tested isolates. Contradictory results were mostly related to 
detection of Plasmodium malariae and Plasmodium ovale in mixed infections, due to an "all-or-none" detection effect at low-level parasitaemia.

Conclusion: A large reservoir of asymptomatic infections was uncovered using the molecular methods. Dot I8S and CYTB, the new methods reported herein are highly sensitive, allow parasite DNA extraction as well as genus- and species-specific diagnosis of several hundreds of samples, and are amenable to high-throughput scaling up for larger sample sizes. Such methods provide novel information on malaria prevalence and epidemiology and are suited for active malaria detection. The usefulness of such sensitive malaria diagnosis tools, especially in low endemic areas where eradication plans are now on-going, is discussed in this paper.

\section{Background}

The first methods for molecular detection of Plasmodium falciparum malaria were published in the 1980s [1-3]. Since then, much progress has been made in DNA extraction, and detection protocols have been simplified. The four human species can be specifically identified, and the more recently developed real-time amplification techniques allow rapid processing of samples and quantification of parasite loads [4-7]. Molecular assessment of point prevalence at the village level has also become feasible. Various field surveys have shown that molecular methods detected up to eight times more Plasmodium spp. infections than microscopy, and that mixed infections could represent up to one third of them [8-11]. Molecular detection tools modify the interpretation of malaria epidemiology, by revealing large reservoirs of asymptomatic infections $[8,12,13]$, cryptic species potentially influencing transmission patterns and clinical outcomes $[14,15]$, as well as shifts in age distribution of Plasmodium spp. infections [16]. The main drawback of molecular detection tools is their cost and workload. Furthermore none of the published methods is adapted to large-scale analysis of thousands of samples. Therefore, most decisions for malaria control programmes still rely on data collected by health services, where malaria is diagnosed using microscopy.

With recent moves towards malaria elimination in a number of countries $[17,18]$, additional methods for detecting infections and infectious reservoirs are needed. Indeed, large-scale studies will be required, including in areas with difficult access to health centers. Such studies require high sensitivity in order to detect asymptomatic carriage and improved species identification in order to adapt treatment. Such needs are best fulfilled by molecular methods, which furthermore would open the possibility to monitor vector control measures. The aim of this study was to improve molecular detection of the four Plasmodium species. To this end, new molecular detection approaches were developed targeting the nuclear $18 \mathrm{~S}$ rRNA gene (18S rDNA), and the mitochondrial cytochrome $b(c y t b)$ gene, enabling mass screening of field samples for epidemiological studies. Both loci were chosen because of their obligate presence, their good intra- species conservation associated with appropriate interspecies variation. The methods were validated using laboratory isolates and used to explore point prevalence in field samples collected during a cross-sectional prevalence survey in three villages in Rattanakiri Province, Cambodia [19]. Results were compared with standard detection methods: microscopy and a published nested PCR method [6], in order to evaluate their performance in terms of sensitivity, specificity and suitability for epidemiological studies.

\section{Methods \\ Study sites}

The three study villages are located in the north-eastern province of Rattanakiri in Cambodia. Rattanakiri is a hilly and forested province, which borders Laos and Vietnam. It is considered one of the most malaria endemic areas in the country. The principal vectors are Anopheles dirus, Anopheles maculatus and Anopheles minimus [20,21]. In 2001, the reported incidence of malaria cases based on laboratory microscopy diagnosis was 21 per 1,000 inhabitants, of which $79.6 \%$ and $20.4 \%$ were due to Plasmodium falciparum and Plasmodium vivax infections, respectively [22].

In September 2001, a baseline cross-sectional prevalence survey conducted by the European Commission-Cambodia Malaria Control Programme (ECMCP) team [19] included 36 "high-risk" villages (less than $1 \mathrm{~km}$ from the forest), which had never been included in any bed net distribution project. Subjects were chosen by random selection of households. Fingerprick blood was collected, and thin/thick blood smears, as well as double blood-spots (approximately $20 \mu \mathrm{L}$ of blood on Whatman $3 \mathrm{M}$ filter paper) were prepared. The blood spots were stored at $20^{\circ} \mathrm{C}$ until analysis. The study reported here concerned three villages: the village of Ping was chosen because it had shown the highest malaria prevalence by microscopy diagnosis. The villages Pahoy and Smach were randomly selected from the list of the 36 ECMCP villages. 


\section{Ethical approval}

The study was approved by the National Ethics Committee of the Kingdom of Cambodia, and all participants gave informed consent.

\section{Microscopy}

Thin smears were fixed in methanol. Both thin and thick smears were stained with 3\% Giemsa for 30 minutes at room temperature. Examination was performed by experienced microscopists at the National Centre for Parasitology, Entomology and Malaria Control in Phnom Penh. At least 100 thick film fields with 1,000× magnification were examined before a slide was considered negative. Malaria case definition was based on the presence or absence of Plasmodium parasites on microscopy slides. Parasite species and stages were confirmed on the thin film. No second reading was possible.

\section{Samples for sensitivity and specificity studies}

For evaluation of DNA extraction methods, cultured $P$. falciparum 3D7 parasites at 1\% parasitaemia were serially diluted ten-fold using uninfected blood. Aliquots of $20 \mu \mathrm{l}$ were spotted on Whatman $3 \mathrm{M}$ filter paper, air-dried and stored at $-20^{\circ} \mathrm{C}$.

For evaluation of the sensitivity of the molecular detection methods, a $200 \mu \mathrm{l}$ red blood cell pellet of a $7.5 \%$ P. falciparum 3D7 culture was extracted by the QIAamp DNA blood kit (QIAGEN, Germany). DNA eluted with $200 \mu \mathrm{l}$ of water was stored at $-20^{\circ} \mathrm{C}$ until analysis. For sensitivity studies, the DNA was serially diluted ten-fold and used for PCR amplification.

The specificity of the molecular diagnosis methods has been assessed with reference DNA of the four species infecting human. DNA from P. falciparum was extracted from a continuous culture of the 3D7 strain, using the QIAamp DNA Blood Mini kit (QIAGEN, Germany). DNA from the $P$. vivax Belem strain was kindly provided by Peter David (Institut Pasteur de Paris, France). Plasmodium malariae and Plasmodium ovale DNA as well as control human DNA from a non-infected person were kindly provided by Georges Snounou (Muséum d'Histoire Naturelle, Paris, France). DNA from patients with $P$. malariae and $P$. ovale single infections, were kindly provided by Eric Legrand (Institut Pasteur de Cayenne, French Guiana). Species identification and single infection were confirmed by cox 1 and cytochrome b genes [23] sequencing and by the "standard" PCR (see below).

\section{DNA extraction}

The blood spots collected in Ping village were processed by 96 well plate extraction method using the QIAamp DNA blood 96 kit (QIAGEN, Germany) as described previously [24]. Cut-out blood-spots were transferred in 96 well plates adapted for $1 \mathrm{~mL}$ volumes, incubated for 90 minutes at $4^{\circ} \mathrm{C}$ in $1 \mathrm{~mL}$ buffer HBS (HEPES $10 \mathrm{mM}, \mathrm{NaCl}$ $140 \mathrm{mM}$, KCl $10 \mathrm{mM}$ ) with $0.5 \% \mathrm{v} / \mathrm{v}$ saponin (SIGMA Aldrich, Germany), then washed twice with $1 \mathrm{~mL}$ HBS using a vacuum pump and a manifold. Subsequently, the recommendations of the kit supplier were followed. Briefly, filter papers were treated for 10 minutes with 180 $\mu \mathrm{L}$ buffer ATL at $85^{\circ} \mathrm{C}$, then digested with $4 \mu$ l of proteinase $\mathrm{K}$ at $100 \mathrm{mg} / \mathrm{mL}$ for 1 hour at $56^{\circ} \mathrm{C}$. After addition of $200 \mu \mathrm{L}$ buffer AL and incubation for 10 more minutes, filter papers were spun down; the supernatant was recovered and mixed with $200 \mu \mathrm{L} \mathrm{100 \%}$ ethanol (SIGMA Aldrich, Germany) at room temperature. The mixture was filtered through QIAamp DNA blood columns using a vacuum pump, then washed once with $500 \mu \mathrm{L}$ buffer AW1 and twice with $500 \mu \mathrm{L}$ buffer AW2. DNA was eluted with 100 $\mu \mathrm{L}$ buffer $\mathrm{AE}$ and stored at $-20^{\circ} \mathrm{C}$.

DNA from the blood spots of the Pahoy and Smach villages was extracted with the Instagene resin (BIORAD, USA) and a 96 well plate in-house protocol adapted from the suppliers recommendations. First, the above described red blood cell lysis in HBS/saponin and the wash steps in HBS were performed. Then, $200 \mu \mathrm{L}$ preheated Instagene resin was added to the filter papers, the mixture incubated for 30 minutes at $56^{\circ} \mathrm{C}$, briefly vortexed, and incubated at $90^{\circ} \mathrm{C}$ for another 30 minutes. After centrifugation at a minimal speed of 4,000 rpm for 20 minutes, the supernatant was recovered and stored at $-20^{\circ} \mathrm{C}$.

\section{8S rDNA: species-specific nested PCR, "standard PCR" (Std)}

The nested PCR method based on the 18S rRNA gene marker [7] adapted for epidemiological studies [6] was considered as reference. After a Plasmodium spp. specific nested PCR with the primer pairs rPLU1/5 and rPLU3/4, the primary PCR product of Plasmodium positive samples was separately amplified with the four species-specific primer pairs $\operatorname{rFAL} 1 / 2, \mathrm{rVIV} 1 / 2, \operatorname{rMAL} 1 / 2, \operatorname{rOVA} 1 / 2$ to identify the species. The published protocol was strictly followed, by using $4 \mu \mathrm{L}$ of DNA and $2 \mu \mathrm{L}$ of primary PCR product for the primary and secondary PCR reactions, respectively. Detection was done by $2 \%$ agarose gel electrophoresis and ethidium bromide staining.

\section{85 rDNA: Genus-specific nested PCR and species- specific dot blot detection (dot I8S)}

Selection of primers and probes for this new detection approach was based on alignment of $18 \mathrm{~S}$ rDNA sequences of human and primate Plasmodium species (Table 1), with primers and genus-specific probes being chosen in zones of maximal sequence similarity of all Plasmodium species, but not with the $18 \mathrm{~S}$ rDNA of other Apicomplexa and human. The V7 variable zone was targeted because of its short length, significant differences between species, but 
Table I: Primers and probes used for Dot-blot I8S rDNA-based detection and primers for cytochrome b-based detection

\begin{tabular}{|c|c|c|}
\hline & $5^{\prime}-3^{\prime}$ sequences & specificity \\
\hline \multicolumn{3}{|c|}{ Dot-blot I8S rDNA-based detection } \\
\hline \multicolumn{3}{|l|}{ Primary PCR } \\
\hline Ps & CTT TCT TgA TTT CTT ggA & P. spp. \\
\hline PPas & ATT CCT CgT TCA AgA TTA A & P. spp. \\
\hline \multicolumn{3}{|l|}{ Nested PCR } \\
\hline Nsl & CAT ggC CgT TTT Tag TTC gTg AAT AT & P. spp. \\
\hline Nas new & CAC gCg TgC AgC CTA gTT & P. spp. \\
\hline \multicolumn{3}{|l|}{ Probes } \\
\hline PLASI & ATA ACg AAC gAg ATC TTA ACC & P. spp. \\
\hline FAL & СТС TAT TTC TСТ СTT СTT TTA AgA & Pf type A, S \\
\hline VIVAI & AAT ATT ggg ATA CgT AAC AgT & Pv type A \\
\hline VIVSI & gTT TCT TAA TCg AAT AgC TgA & Pv type $S$ \\
\hline MAL2b & AgA ATA TAg ATA AAT TgT gCT AA & $\mathrm{Pm}$ \\
\hline OVA3 & TgA AAT TgA ATA TAg CTg AAT T & Po \\
\hline \multicolumn{3}{|c|}{ Cytochrome b-based detection } \\
\hline \multicolumn{3}{|l|}{ Primary PCR } \\
\hline GCDW2 & Cgg TCg CgT CCg gTA gCg TCT AAT gCC TAg ACg TAT TCC TgA TTA TCC Ag & P. spp. \\
\hline GCDW4 & CgC ATC ACC TCT ggg CCg CgT gTT TgC TTg ggA gCT gTA ATC ATA ATg Tg & P. spp. \\
\hline \multicolumn{3}{|c|}{ 与 } \\
\hline PLASI & gAg AAT TAT ggA gTg gAT ggT g & P. spp. \\
\hline PLAS2 & Tgg TAA TTg ACA TCC AAT CC & P. spp. \\
\hline
\end{tabular}

Specificity of primers and probes is indicated as follows: $P$. spp. $=$ Plasmodium spp., $P f / P v / P m / P o=P$. falciparum, $P$. vivax, $P$. malariae and $P$. ovale, respectively, type $\mathrm{A} / \mathrm{S}=$ stage-specific $18 \mathrm{~S} r \mathrm{DNA}$ type $\mathrm{A}$ and $\mathrm{S}$, respectively.

good similarity of stage-specific copies within each species. The choice of the species-specific probes was based on the intention to detect all stage-specific sequences of the same species. For each primer and probe, two to four different designs were experimentally evaluated, using the above-mentioned reference DNA samples, before making a final choice for highest possible sensitivity and specificity.

The primary PCR was performed in a $20 \mu \mathrm{L}$ volume with $3 \mu \mathrm{L}$ DNA, $0.4 \mu \mathrm{M}$ of Ps and PPas primers (Table 1), 0.2 $\mathrm{mM}$ dNTP, $1.5 \mathrm{mM} \mathrm{MgCl}_{2}$, and $1 \mathrm{U}$ of Taq DNA polymerase (Solis Biodyne, Estonia), using the following cycling program: 4 minutes at $95^{\circ} \mathrm{C}$, then 30 cycles of 30 seconds at $95^{\circ} \mathrm{C}, 90$ seconds at $51^{\circ} \mathrm{C}, 2$ minutes at $64^{\circ} \mathrm{C}$, and final extension for 15 minutes at $64^{\circ} \mathrm{C}$. One $\mu \mathrm{L}$ of primary PCR product was used for nested PCR under the same conditions, using the primers Ns1 and Nas new (Table 1), except for the annealing $\left(60^{\circ} \mathrm{C}\right)$ and extension $\left(66^{\circ} \mathrm{C}\right)$ temperatures, and the number of cycles (25).

The colorimetric Dot-blot detection was designed for a 96 well plate format, using the Bio-Dot Microfiltration apparatus (BIORAD, USA). The protocol was adapted from the suppliers recommendations. Briefly, $10 \mu \mathrm{L}$ of nested PCR product were denatured 15 minutes at $40^{\circ} \mathrm{C}$ in $0.2 \mathrm{M}$ $\mathrm{NaOH}$, then transferred to the Bio-Dot apparatus mounted with a TE (Tris $10 \mathrm{mM}$, EDTA $1 \mathrm{mM}, \mathrm{pH} 8.0$ ) soaked Hybond $\mathrm{N}+$ membrane (Amersham, UK). After successive filtration of the PCR product and $500 \mu \mathrm{L} 0.2 \mathrm{M}$ $\mathrm{NaOH}$ using a vacuum pump, the membrane was rinsed in SSC $2 \times($ SSC $20 \times$ : NaCl $3 \mathrm{M}, \mathrm{Na}$ citrate $0.3 \mathrm{M}, \mathrm{pH} 7.0)$, air-dried and exposed for 5 minutes to UV light for DNA crosslinking. The subsequent steps were performed in sealable hybridization bags (Roche Diagnostics, France) and a waterbath. After 2 hours pre-hybridization at $40^{\circ} \mathrm{C}$ in Denhardt's hybridization buffer (SSC $5 \times, 0.1 \%$ Ficoll, $0.1 \%$ polyvinylpyrrolidone, $0.1 \%$ bovine serum albumine, $0.5 \%$ SDS), $10 \mathrm{pmol} / \mathrm{mL}$ of digoxigenine-labeled probe (PROLIGO, France) was added and incubation continued overnight or 3 hours minimum (probes sequences: Table 1).

Wash steps were as follows : two times 5 minutes in SSC $2 \times$, SDS $0.1 \%$ at room temperature, 15 minutes in SSC $1 \times$, SDS $0.1 \%$ at $40^{\circ} \mathrm{C}$, and two times 10 minutes in SSC $0.1 \times$, SDS $0.1 \%$ at $40^{\circ} \mathrm{C}$. For the revelation, the membrane was incubated for 5 minutes in "Washing buffer" and for 1 hour in "Blocking Solution" (DIG Wash and Block buffer set, Roche Diagnostics, France) at room temperature, then 30 minutes in "Blocking Solution" with 1,000× diluted anti-digoxigenine antibody conjugated to alkaline phosphatase (Roche Diagnostics, France), then 15 minutes in "Washing Solution" and 3 minutes in "Detection buffer". Colorimetric revelation was achieved with $50 \times$ diluted NBT/BCIP in "Detection buffer" (NBT/BCIP stock solu- 
tion, Roche Diagnostics, France). After having obtained a satisfying signal intensity, reaction was stopped by rinsing in TE buffer, and the membrane was scanned in a GS 800 densitometer (BIORAD, USA).

Sequences of Plasmodium genus-specific primers for nested PCR amplification and probes for Dot-blot colorimetric detection on membranes were selected after alignment of the following $18 \mathrm{~S} r \mathrm{DNA}$ sequences: $P$. falciparum: M19172, M19173; P. vivax: U07367, U93234, AF145335, U07368, U93095; P. malariae: M54897; P. ovale: L48986, AJ001527; Plasmodium simium: U69605; Plasmodium fragile: M61722; Plasmodium knowlesi: U83876; Plasmodium cynomolgi: L08241; Plasmodium reichenowi: Z25819; Plasmodium inui: U72541; Plasmodium brasilianum: AF130735; Toxoplasma gondii: L37415; human: X03205.

\section{Cytochrome b: genus-specific nested PCR and SNP identification (CYTB)}

Two primer sets were designed for nested PCR amplification of a large portion of the cytochrome $b$ gene, with specificity to all human and primate Plasmodium species, but excluding other Apicomplexa or human DNA. Primers are presented in Table $1[23,25]$. One $\mu \mathrm{L}$ DNA was amplified with $1 \mu \mathrm{M}$ of each primer, $0.2 \mathrm{mM} \mathrm{dNTP}$ (Solis Biodyne, Estonia), $3 \mathrm{mM} \mathrm{MgCl}_{2}$, and $2 \mathrm{U}$ Taq DNA polymerase (Solis Biodyne, Estonia), using the following cycling program : 5 minutes at $94^{\circ} \mathrm{C}$, then 40 cycles of 30 seconds at $94^{\circ} \mathrm{C}, 90$ seconds at $60^{\circ} \mathrm{C}, 90$ seconds at $72^{\circ} \mathrm{C}$, and final extension 10 minutes at $72^{\circ} \mathrm{C}$. For the nested-PCR, $2 \mu \mathrm{L}$ of primary PCR product were amplified under the same conditions, except for the $\mathrm{MgCl}_{2}$ concentration $(2.5 \mathrm{mM})$. PCR products of 815 base pairs were detected by standard $2 \%$ agarose gel electrophoresis and ethidium bromide staining. Double strand sequencing of PCR products was performed by the Genopole laboratory of the Institute Pasteur of Paris. Sequences were analysed with the Seqscape 2.0 software (Applied Biosystems, USA) to identify species-specific SNP combinations. An algorithm based on 11 selected SNPs has previously been developed based on an alignment of published cytochrome $b$ reference sequences of $P$. falciparum, $P$. vivax, $P$. malariae and $P$. ovale, allowing identification of each species (Figure 1), as well as all possible combinations of mixed infections.

\section{Statistical analysis}

All statistical analyses were performed by using STATA SE 8 software (Stata Corporation, College Station, TX). Exact McNemar test has been used to compare frequencies in matched data of infections.

\section{Results Comparison of DNA extraction methods}

To compare the QIAamp 96 and Instagene 96 DNA extraction methods, filter paper blood spots of ten-fold serially diluted blood (ranging from $1 \%$ to $10-5 \%$ parasitaemia) were extracted in parallel using these two methods. DNA was amplified using the standard nested PCR method targeting $18 S r D N A$. Both methods allowed repeated detection of $10^{-4}$ dilutions, whereas the $10^{-5}$ dilutions were only detected in one of two experiments. This "all or none" phenomenon at detection limit has been reported previously [6,7]. The QIAamp 96 protocol was discarded because of sporadic foaming during the washing steps (increasing the risk of cross-contamination of flanking wells), the higher workload and more expensive kits, compared to the Instagene 96 method.

\section{Screening of field samples by microscopy and "standard" nested PCR}

A total number of 337 samples were screened in the three villages. Microscopy diagnosis revealed a Plasmodium prevalence of $59.8 \%, 39.6 \%$ and $29.1 \%$ in Ping $(\mathrm{n}=102)$, Smach $(\mathrm{n}=101)$, and Pahoy $(\mathrm{n}=134)$, respectively. The infections consisted in P. falciparum (prevalence of $48.0 \%$, 33.7 and $28.4 \%$, respectively), $P$. vivax $(2.0 \%, 1.0 \%$ and $0.7 \%$, respectively) or a mixed infection of both $P$. falciparum and P. vivax (9.8\%, 5.0\% and 0\%, respectively).

The published "standard" PCR detected significantly (exact McNemar test, $\mathrm{p}<0.0001$ ) more Plasmodium spp. infections than microscopy in all three villages (Figure 2). Table 2 shows the comparison with microscopy for the village Ping, which had the highest microscopy-based malaria prevalence of all 36 initially surveyed villages (Table 2), and for Smach and Pahoy villages (Table 2). The data show that molecular detection multiplied the estimated Plasmodium spp. prevalence by 1.3 in Ping, and by 2.2 in Smach and Pahoy. P. malariae and P. ovale were detected in the three villages with a prevalence of $15.1 \%$ (range 12.7\%-15.7\%) and 6.5\% (range 3.9\%-7.9\%), respectively, although these species were considered rare or non-existent in Cambodia and had not been detected in these samples by microscopy. Moreover, the PCR approach revealed a much higher rate of mixed infections (39\% and 31\% prevalence in Ping and Smach/Pahoy, respectively) than microscopy, with numerous triple or quadruple infections.

A total of 12 samples were considered microscopy positive, but tested negative by "standard" nested PCR (Std). Out of these, eight samples were subsequently found to be Plasmodium positive by at least one of the newly developed and more sensitive molecular detection methods (Dot18S and CYTB, see following paragraph). All four remaining samples displayed low parasite densities by microscopy (rating of $1+$ ). 


\begin{tabular}{|c|c|c|c|c|c|c|c|c|c|c|c|}
\hline $\begin{array}{c}\text { SNP } \\
\text { position }\end{array}$ & 276 & 330 & 381 & 417 & 510 & 570 & 606 & 630 & 714 & 793 & 918 \\
\hline$P f$ & $\mathrm{~T}$ & $T$ & $C$ & $T$ & $T$ & $C$ & $\mathrm{~T}$ & $T$ & $A$ & $C$ & $\mathrm{~T}$ \\
\hline$P V$ & $C$ & $A$ & $\mathrm{~T}$ & $\mathrm{~T}$ & $\mathrm{~T}$ & $T$ & $\mathrm{~T}$ & C & $\mathrm{T}$ & $T$ & $\mathrm{~T}$ \\
\hline$P m$ & $\mathrm{~T}$ & $A$ & $\mathrm{~T}$ & $A$ & $\mathrm{~T}$ & $\mathrm{~T}$ & $C$ & $\mathrm{~T}$ & $A$ & $\mathrm{~T}$ & $\mathrm{~T}$ \\
\hline Po & $\mathrm{T}$ & $A$ & A & $\mathrm{T}$ & $C$ & $C$ & $\mathrm{~T}$ & C & $A$ & $\mathrm{~T}$ & $C$ \\
\hline $\begin{array}{c}\text { Sample } \\
\# 022\end{array}$ & 1 & D & i & & & 1 & 1 & 4 & 1 & 0 & \\
\hline $\begin{array}{c}\text { Sample } \\
\# 066\end{array}$ & & & & & & & & $\lambda$ & & & \\
\hline $\begin{array}{c}\text { Sample } \\
\# 067\end{array}$ & & & & & & & & & & & \\
\hline
\end{tabular}

Figure I

Species-specific combinations of SNP in the cytochrome b gene. I I SNPs were selected allowing categorical identification of the Plasmodium species. Three examples of SNP sequencing data are shown: sample \#22 = mixed infection of $P$. falciparum and $P$. vivax, sample \#66 = P. falciparum, and sample \#67 = P. malariae (Seqscape 2.0 software, Applied Biosystems USA). Those SNPs were shown to be robust and never presented contradictory results. $P f / P v / P m / P o=P$. falciparum, $P$. vivax, $P$. malariae and $P$. ovale, respectively.

\section{Comparison of molecular detection approaches for genus (Plasmodium spp.) detection}

The sensitivity of the three molecular detection methods was assessed by two experiments with ten-fold serially diluted DNA samples of known parasite content (corresponding to a parasitaemia range from 750,000 down to 0.0075 parasites per $\mu \mathrm{L}$ blood, $\mathrm{p} / \mu \mathrm{L})$. The "standard" PCR detected down to $7.5 \mathrm{p} / \mu \mathrm{L}$, with an "all or none" phenomenon for $0.75 \mathrm{p} / \mu \mathrm{L}$. Higher sensitivity was obtained with dot $18 \mathrm{~S}$ and CYTB methods, which detected down to 0.75 $\mathrm{p} / \mu \mathrm{L}$ and $0.075 \mathrm{p} / \mu \mathrm{L}$, respectively.

The estimated prevalence rate of plasmodial infections was significantly higher with CYTB than with dot $18 \mathrm{~S}$ (exact McNemar test, $\mathrm{p}<0.03$ ) and significantly higher with the dot $18 \mathrm{~S}$ than the "standard" nested PCR method $(\mathrm{p}<0.03)$ (Figure 2).

The sample-by-sample comparison of Plasmodium spp. detection showed that the three molecular methods were in agreement for $82.8 \%$ of samples, whereas the remainder was detected either by only one $(6.2 \%)$ or by two methods (11.0\%, Figure 3). The dot $18 \mathrm{~S}$ detection approach displayed a sensitivity of $95.3 \%$ and a specificity of $66.7 \%$, while a higher sensitivity $(97.3 \%)$ and a lower specificity (55.7\%) were obtained with the CYTB detection, compared to the "standard" method. These relatively low specificities were due to 27 and 36 "standard" negative samples testing positive with the methods dot $18 \mathrm{~S}$ and CYTB, respectively (Figure 3), most probably because of their higher sensitivities previously shown with serially diluted control samples. In other words they were indeed due to their checking positive samples classified as negative (false negatives) by the "standard" method.

\section{Comparison of the molecular approaches for species- specific detection}

The three molecular methods had different sensitivities for detecting the four Plasmodium species (Figure 4). Paired comparison of the prevalence measured by the 


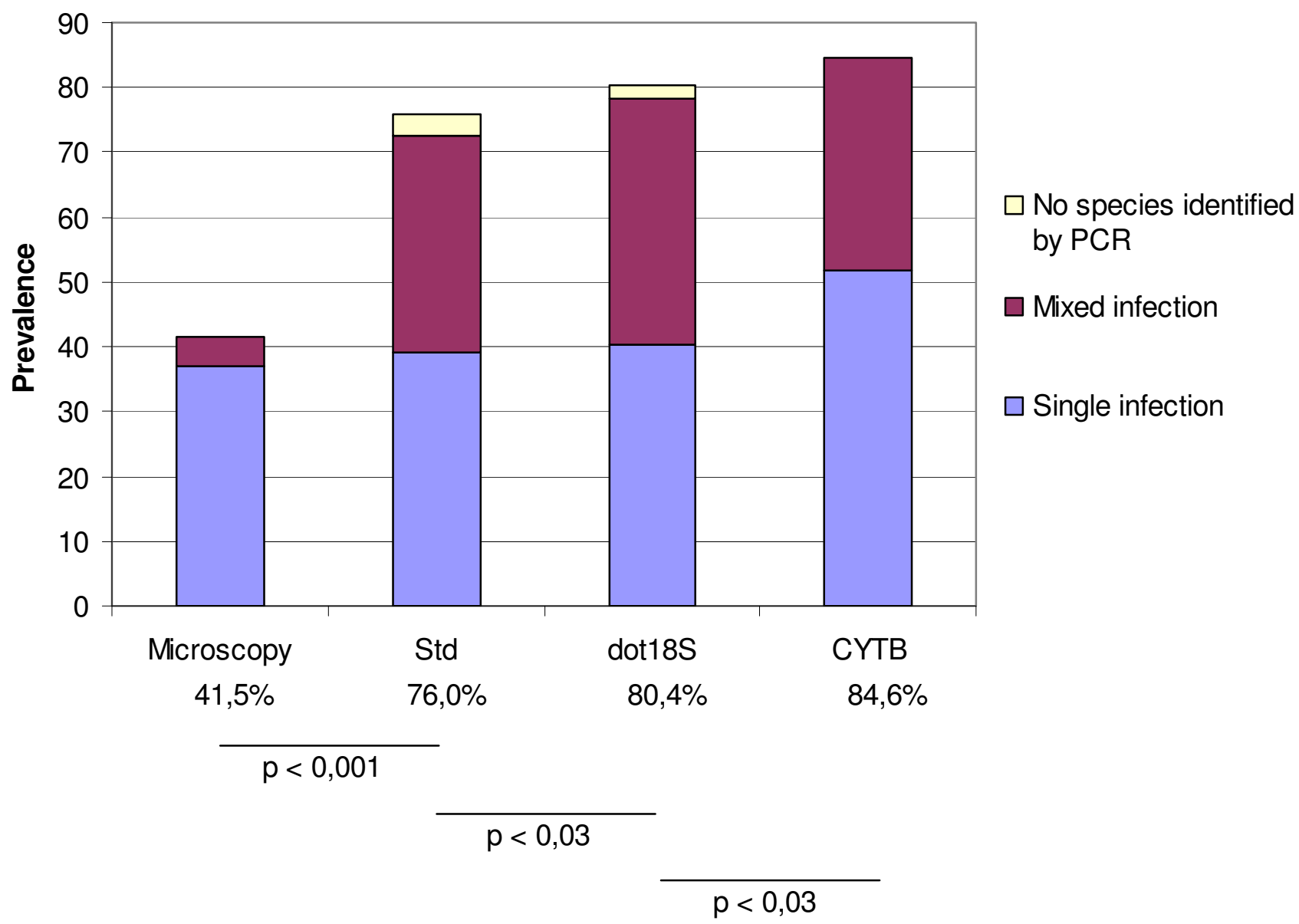

Figure 2

Plasmodium prevalence measured by microscopy and molecular methods. Significant (exact McNemar tests) differences in prevalence rates of Plasmodium spp. infections $(n=337)$ were detected by microscopy, "standard" nested PCR (Std), I 8S rDNA-based nested PCR and Dot-blot detection (dot I8S), and by cytochrome $b$-based nested PCR and SNP identification (CYTB). The proportion of mixed infections detected by the molecular methods was also considerably higher than by microscopy (43.7\% for Std, $47.2 \%$ for dot I8S, and $38.9 \%$ for CYTB, compared to $10.7 \%$ for microscopy).

three methods for Plasmodium spp (Std 76.0\%, dot18S $80.4 \%$, CYTB $84.6 \%$ ) and for P. falciparum infections (Std $63.8 \%$, dot18S 68.3\%, CYTB 71.8\%) showed that dot $18 \mathrm{~S}$ and CYTB detected significantly more Plasmodium spp (exact McNemar test: Std/dot18S = 0.0237; Std/CYTB = 0.0000 ; dot $18 \mathrm{~S} / \mathrm{CYTB}=0.0243$ ) and $P$. falciparum (exact McNemar test: Std/dot18S = 0.0357; Std/CYTB = 0.0003; dot18S/CYTB $=0.0807$ ) infections than the "standard" method. Significantly higher $P$. vivax prevalence was detected by the dot $18 \mathrm{~S}$ method, compared to the CYTB diagnosis $(38.6 \%$ versus $30.6 \%$, exact McNemar test: dot18S/CYTB = 0.0009), while the "standard" method measured a prevalence of 33.5\% (exact McNemar test: Std/dot18S = 0.0270; Std/CYTB = 0.2888). Comparable prevalences were observed for P. malariae (Std 15.1\%, dot18S 16.6\%, CYTB 14.2\%; exact McNemar test: Std/ $\operatorname{dot} 18 \mathrm{~S}=0.4244 ; \operatorname{Std} / \mathrm{CYTB}=0.7493 ; \operatorname{dot} 18 \mathrm{~S} / \mathrm{CYTB}=$ 0.2153 ) and $P$. ovale (Std 6.5\%, dot $18 \mathrm{~S}$ 6.2\%, CYTB 5.0\%; exact McNemar test: Std/dot18S = 1.0000; Std $/$ CYTB = $0.4244 ; \operatorname{dot} 18 \mathrm{~S} / \mathrm{CYTB}=0.4807$ ).

With the "standard" and dot18S methods, some samples tested negative with the species-specific detection ("standard": nested PCR, dot18S: hybridization of probes) even though they had been positive with the previous genusspecific nested PCR (Std: 12 samples, dot18S: 7 samples). The comparison of the species identifications sample by sample and species by species showed that agreement of the three molecular methods was best for P. falciparum: the three techniques consistently detected $P$. falciparum in 193 samples (see Additional file 1), out of 262 P. falciparum-positive samples detected by at least one of the 
Table 2: Comparison of malaria diagnosis by microscopy and "standard" nested PCR The comparison between microscopy and "standard" PCR diagnosis is shown for samples collected in the Ping village $(n=102$, Table 2A) and for samples collected in the Smach and Pahoy villages $(n=235$, Table 2B)

Standard PCR

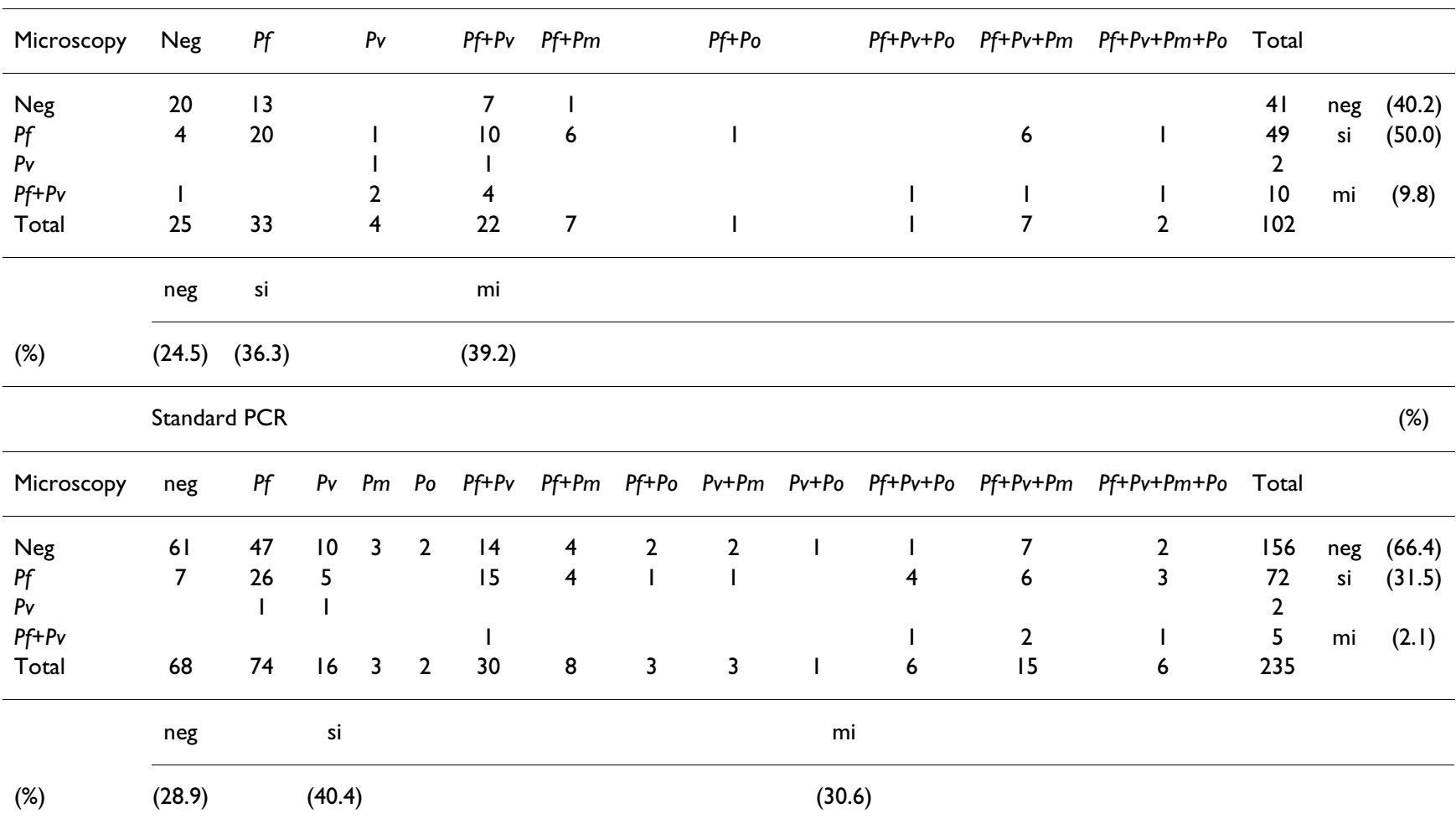

$P f / P v / P m / P o=P$. falciparum, $P$. vivax, $P$. malariae and $P$. ovale; neg $=$ negative $;$ si $=$ single infection; mi $=$ mixed infection

techniques (agreement rate of $73.7 \%$ ). The agreement rates were much lower for $P$. vivax $(42.0 \%), P$. malariae $(36.8 \%)$, and lowest for $P$. ovale $(18.4 \%)$. The large majority of the samples with no agreement consisted of conflicting detection of $P$. malariae and $P$. ovale.

\section{Discussion}

The WHO gold standard method for malaria diagnosis is microscopy. It is considered inexpensive and field adapted, even though it is time-consuming and requires specifically trained personnel. Molecular detection methods achieve much higher detection sensitivities $[1,26]$, and they are better adapted to automation of the process and objective reading of results by machines. This potential makes them a valuable option for large-scale epidemiologic studies. Unfortunately few efforts have been spent on developing the high-throughput approaches needed for such studies.

The 18S rRNA gene is the most frequently cited marker for malaria detection. It is composed of highly conserved regions which can be targeted for a qualitative detection of Plasmodium spp., and of variable zones allowing species identification [4-7]. However, the 18S rRNA genes in Plas- modium spp. also have unusual properties, such as the existence of three stage-specific A-, S- and O-types, as well as copy number and strain-specific sequence variations [27-29]. Primers and probes have to be designed accordingly, since strain-specific variations can perturb the detection $[30,31]$. The copy number of the rRNA gene varies from four to eight $[28,29]$. The design of primers and probes for the dot18S method was based on published sequences alignment, by targeting the Zone V7 which displays maximal inter-species sequence variation, while allowing genus-specific identification as well as detection of the $18 S$ rRNA A- and S- type genes of P.falciparum and P.vivax. $18 \mathrm{~S}$ rRNA polymorphism could be a significant biais for molecular when targeting this gene, anyway it is still considered as the "gold standard" for species identification. The cytochrome $b$ gene is highly conserved and has mainly been used for phylogenetic studies [23,32-35]. The gene is located on the mitochondrial genome, which occurs at an estimated number of 30-100 copies per parasite [36-38], and as a consequence is predicted to permit more sensitive detection than the $18 S$ rRNA gene.

Analysis of more than 300 field samples collected in Cambodia demonstrated the added value of the molecular 


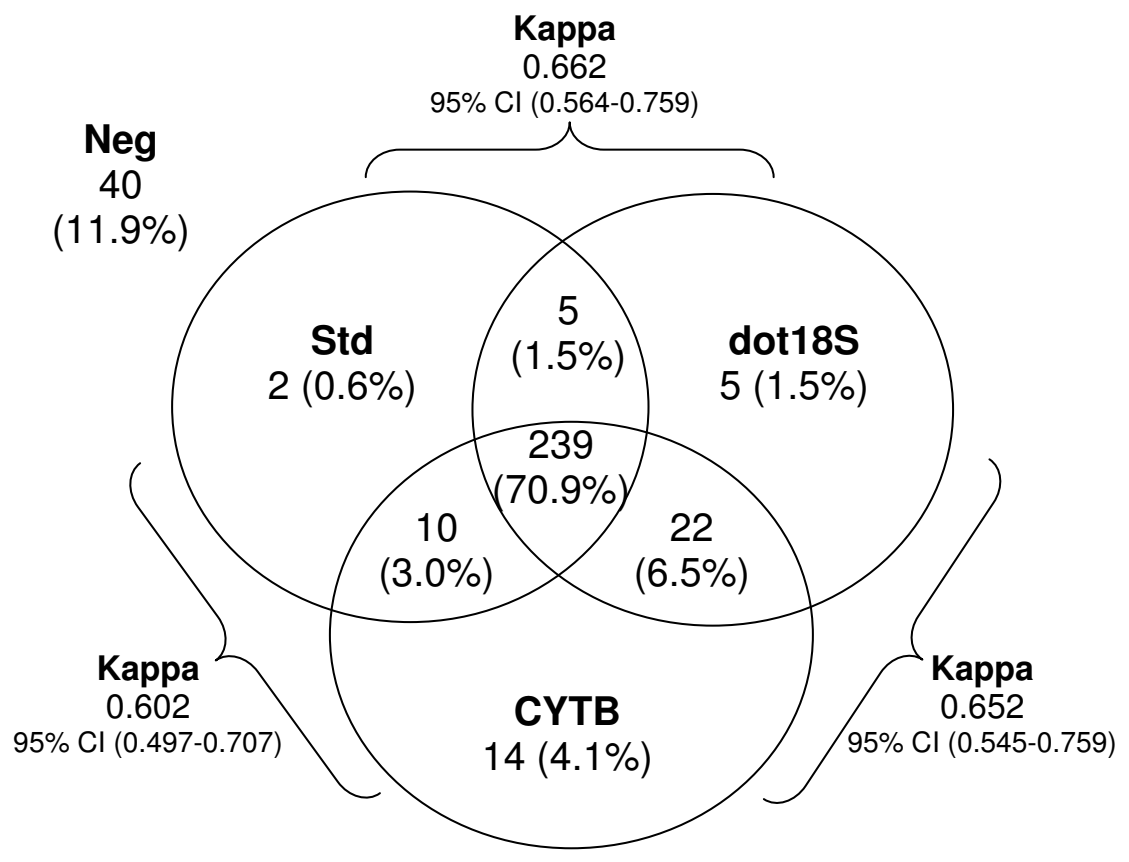

Figure 3

Agreement of Plasmodium spp. detection by the three molecular methods. The cytochrome b-based detection method (CYTB) showed the highest number of Plasmodium infections ( 285 samples), while 271 and 256 infections were observed with the Dot-blot detection (dot I8S) and the "standard" nested PCR (Std), respectively. The three methods agreed on the detection of 239 positive and 40 negative samples (agreement rate of $82.8 \%$ ). Kappa coefficient (Kappa) is calculated between those three methods with $95 \%$ Confidence Interval $(95 \% \mathrm{Cl})$.

approach. Compared to microscopic diagnosis, an up to two-fold higher Plasmodium prevalence was evidenced, revealing a previously unsuspected reservoir of asymptomatic infections. Mixed infections were detected in about one third of the villagers, a much higher figure than reported in neighbouring countries $[7,10,11]$. Such information is crucial for the National Malaria Control Programme, as mixed infections could influence gametocyte carriage and clinical outcome $[14,15,39]$.

The performance of the two new molecular detection approaches outranged the published "standard" nested PCR method. The cytochrome b-based CYTB method was the most sensitive, likely because it targets the multiple copies of mitochondrial genome present in each parasite. Probably for the same reason, it also detected higher rates of Plasmodium spp. and $P$. falciparum infections among the field samples. Plasmodium vivax was better identified with the dot $18 \mathrm{~S}$ detection approach, maybe because two independent experiments with the A-type and S-type specific probes were combined, increasing the chance of detecting low parasite densities in P. vivax infections. The two $18 \mathrm{~S}$ rDNA-based methods (std and dot18S) detected some samples by genus-specific but not by species-specific amplification/probe hybridization. The reason for this is uncertain but could be due to mutations in the targeted $18 S$ rDNA sequences, or, in the case of the "standard" method, to copy number variations of the stage-specific gene types amplified by the "standard" method (P. falciparum: S-type, P. vivax: A-type), as previously reported $[28,30,31]$.

The three molecular methods agreed well on the detection of Plasmodium spp. infections. However, the different species were not detected/identified with the same level of agreement, with most disagreements being observed for $P$. malariae and $P$. ovale. This is most probably due to the previously described "all-or-none" effect occurring at threshold parasite densities. Low-levels parasitaemias of $P$. malariae and $P$. ovale are especially frequent in mixed infections, partly because of the species characteristics, partly because of a density-dependant regulation mechanism [40]. These species are, therefore, easily overlooked by microscopy, when $P$. falciparum or $P$. vivax are the major species. This also explains the largely higher number of mixed infection detected with molecular biology tools compared to microscopic examinations. 


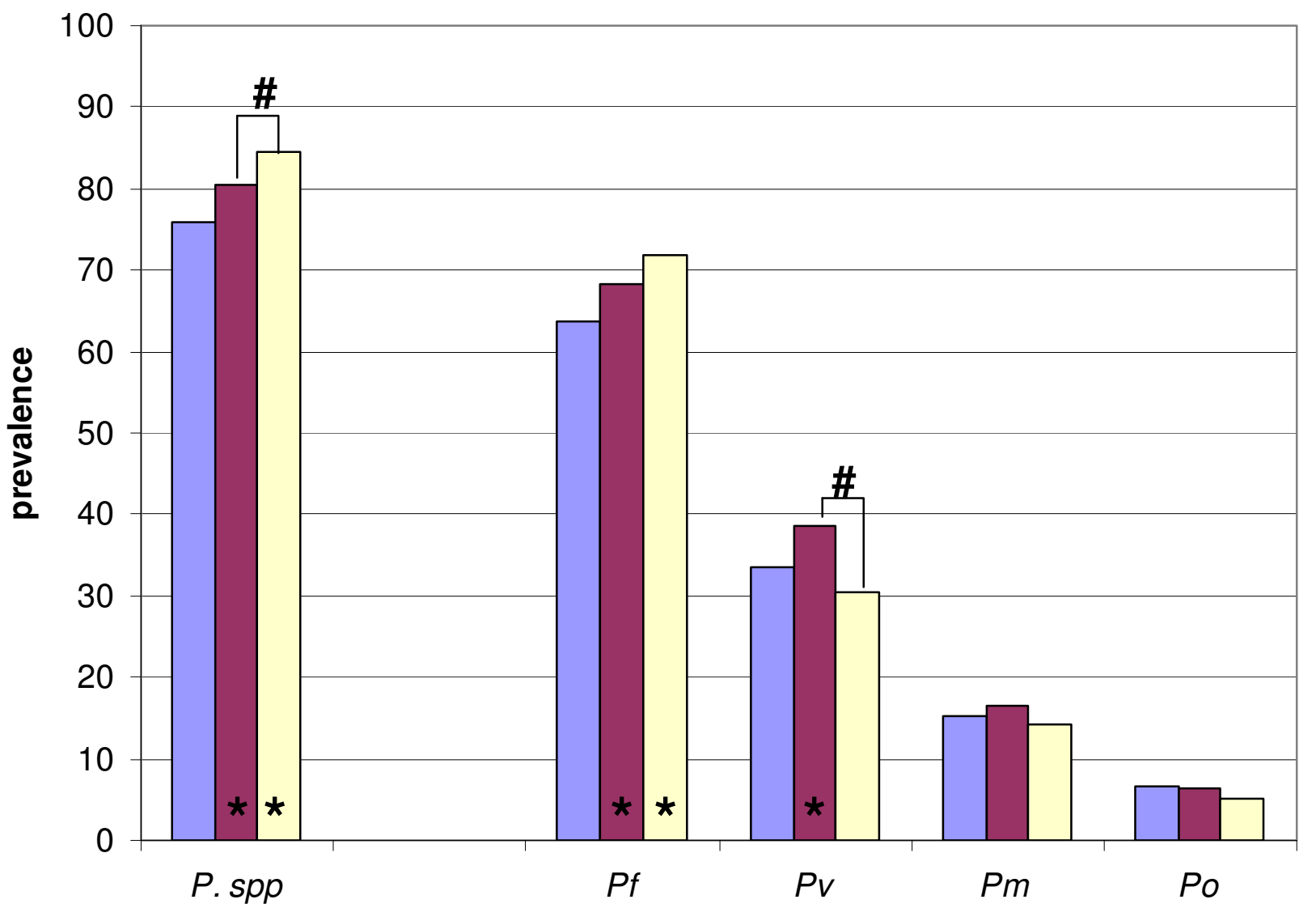

Std $\square \operatorname{dot} 18 \mathrm{~S} \square$ CYTB

\section{* : method displaying significant different prevalences compared to Std using McNemar test . \# : significant different prevalences between dot18S and CYTB using McNemar test.}

Figure 4

Genus- and species-specific detection by three molecular methods. Std = "standard" nested PCR, dot I8S = I8S rDNA based Dot blot detection, CYTB = cytochrome $b$ based detection with SNP identification, $P$. spp. = Plasmodium spp., PfIPv/Pm/Po $=P$. falciparum, $P$. vivax, $P$. malariae and $P$. ovale, respectively.

The weak point of the newly developed molecular techniques remains the visual interpretation of spots with a certain background (dot18S) and of potentially double electrophoresis peaks (CYTB). This may be solved by using straightforward bioinformatics software for analysis. Another weak point could be non-detection of parasites by molecular methods while detected by microscopy, which occurred in a number of samples in this study. The non-detection by molecular methods was most probably due to errors of DNA extraction (false negatives) or error on slide reading (false positives), especially for four samples, which were negative by all three molecular diagnosis methods. Non-detection because of atypical mutations in primer- and/or probes hybridization zones could be a third explanation for these results.

New large-scale detection methods should obviously be evaluated with numerous field samples from different endemic areas of the world, to assess their robustness with respect to possible sequence variations in wild parasites. This is particularly important for the more variable $18 \mathrm{~S}$ rRNA marker as previous reports indicate that Plasmodium parasites from South-East Asia, including North-East Cambodia, display a particularly large heterogeneity of $18 \mathrm{~S}$ rRNA gene sequences (S. Incardona et al, unpublished work) $[24,30,31]$. Furthermore, infections with low 
parasite densities and mixed species, including $P$. malariae and $P$. ovale, are common in this part of the world (S. Incardona et al, unpublished work) [11,14]. It is therefore important to note that this study, with its promising results, provides a field evaluation of the new detection methods in a relatively difficult context.

Even if the two newly developed techniques allow detection of Plasmodium genus and species at a much larger scale than the standard molecular diagnosis methods, the ultimate goal of this work is to develop new approaches allowing analysis of thousands of field samples. Many phases of the current processes are amenable to adaptation to pipetting robots, reducing contamination risks, manipulation errors and, therefore, false positive and false negative results. In particular, DNA extraction by pipetting robots and detection with the real-time amplification approach help to reduce the number of manipulation steps and opening of tubes, while allowing to deal with a higher number of samples. Feasibility studies with reference DNA samples and the above described field samples have shown that the dot 18 S detection approach, using the same primers and probes, could be transferred to a microarray format (S. Incardona et al, unpublished work). Similarly, higher throughput detection of the cytochrome $b$ PCR products by RFLP/dHPLC analysis or by microarray has successfully been evaluated (N. Steenkeste et al, unpublished work). These higher throughput approaches should allow Plasmodium detection and species identification of thousands of samples in mass screening programme in less than three days of lab work $(\mathrm{N}$. Steenkeste et al, unpublished work).

\section{Conclusion}

This work is a first step on the way to developing highthroughput parasite detection approaches for large-scale field studies. Highly sensitive detection of malaria parasites can be achieved. Sensitive molecular methods will prove useful in studies exploring malaria epidemiology, risk factors for symptomatic and asymptomatic infections, interaction of species and importantly in monitoring efficacy and effectiveness of the scaling up of malaria control efforts. Indeed, classical control measures and symptombased treatment are inefficient in controlling asymptomatic carriers $[13,33,41]$, yet controlling asymptomatic infections and targeting this reservoir are critical arms of malaria elimination programmes [42].

\section{Competing interests}

The authors declare that they have no competing interests.

\section{Authors' contributions}

NS, LD and FA conceived and designed the genus-specific nested PCR and SNP identification based on the cytochrome $b$ gene; SI, FA and TF conceived and designed the genus-specific nested PCR and species-specific dot blot detection based on the $18 S$ rDNA gene; MTE sequenced the cytochrome $b$ PCR products; SH, TS and SD lead the field work; NS, SI, SC managed the experimental procedure and performed the laboratory work; NS, SI, CR, TF, FA participated in the statistical analyses; NS, SI, LD, MTE, $\mathrm{PL}, \mathrm{SH}, \mathrm{TS}, \mathrm{SD}, \mathrm{CR}, \mathrm{OMP}, \mathrm{TF}, \mathrm{FA}$ drafted and critically revised the manuscript. All authors read and approved manuscript.

\section{Additional material}

\section{Additional File 1 \\ Agreement of Plasmodium falciparum detection by the three molec- ular methods. Std = "standard" nested PCR, dot18S =18S rDNA based Dot blot detection, $С Y T B=$ cytochrome b based detection with SNP identification. Kappa coefficient (Kappa) is calculated between those three methods with 95\% Confidence Interval (95\% CI). \\ Click here for file \\ [http://www.biomedcentral.com/content/supplementary/1475- 2875-8-86-S1.doc]}

\section{Acknowledgements}

The authors thank the staff of the National Center for Parasitology, Entomology and Malaria Control as well as the staff of the European Commission National Malaria Control Programme for sample collection and for the initial examination of the blood slides. The work was funded by the PAL+ program of the French Ministry of Research and New Technologies and and a grant from Institut Pasteur (Modipop project). SI and NS were granted by a "Foundation Jeunesse Internationale" fellowship of the "Fondation de France".

\section{References}

I. Barker RH Jr, Suebsaeng L, Rooney W, Alecrim GC, Dourado HV, Wirth DF: Specific DNA probe for the diagnosis of Plasmodium falciparum malaria. Science 1986, 23 I: | 434-| 436.

2. Franzen L, Westin G, Shabo R, Aslund L, Perlmann H, Persson T, Wigzell $H$, Pettersson $U$ : Analysis of clinical specimens by hybridisation with probe containing repetitive DNA from Plasmodium falciparum. A novel approach to malaria diagnosis. Lancet 1984, I:525-528.

3. Pollack Y, Metzger S, Shemer R, Landau D, Spira DT, Golenser J: Detection of Plasmodium falciparum in blood using DNA hybridization. Am J Trop Med Hyg 1985, 34:663-667.

4. de Monbrison F, Angei C, Staal A, Kaiser K, Picot S: Simultaneous identification of the four human Plasmodium species and quantification of Plasmodium DNA load in human blood by real-time polymerase chain reaction. Trans $R$ Soc Trop Med Hyg 2003, 97:387-390.

5. Rougemont M, Van Saanen M, Sahli R, Hinrikson HP, Bille J, Jaton K: Detection of four Plasmodium species in blood from humans by I8S rRNA gene subunit-based and species-specific realtime PCR assays. J Clin Microbiol 2004, 42:5636-5643.

6. Singh B, Bobogare A, Cox-Singh J, Snounou G, Abdullah MS, Rahman $H A$ : A genus- and species-specific nested polymerase chain reaction malaria detection assay for epidemiologic studies. Am J Trop Med Hyg 1999, 60:687-692.

7. Snounou G, Viriyakosol S, Zhu XP, Jarra W, Pinheiro L, do Rosario $\mathrm{VE}$, Thaithong S, Brown KN: High sensitivity of detection of human malaria parasites by the use of nested polymerase chain reaction. Mol Biochem Parasitol 1993, 61:315-320.

8. Alves FP, Durlacher RR, Menezes MJ, Krieger H, Silva LH, Camargo EP: High prevalence of asymptomatic Plasmodium vivax and 
Plasmodium falciparum infections in native Amazonian populations. Am J Trop Med Hyg 2002, 66:641-648.

9. Singh B, Cox-Singh J, Miller AO, Abdullah MS, Snounou G, Rahman HA: Detection of malaria in Malaysia by nested polymerase chain reaction amplification of dried blood spots on filter papers. Trans R Soc Trop Med Hyg 1996, 90:519-52I.

10. Snounou G, Pinheiro L, Goncalves A, Fonseca L, Dias F, Brown KN do Rosario VE: The importance of sensitive detection of malaria parasites in the human and insect hosts in epidemiological studies, as shown by the analysis of field samples from Guinea Bissau. Trans R Soc Trop Med Hyg 1993, 87:649-653.

II. Toma H, Kobayashi J, Vannachone B, Arakawa T, Sato Y, Nambanya $S$, Manivong K, Inthakone S: A field study on malaria prevalence in southeastern Laos by polymerase chain reaction assay. Am J Trop Med Hyg 200I, 64:257-26I.

12. Babiker HA, Abdel-Muhsin AM, Ranford-Cartwright LC, Satti G, Walliker D: Characteristics of Plasmodium falciparum parasites that survive the lengthy dry season in eastern Sudan where malaria transmission is markedly seasonal. Am J Trop Med Hyg 1998, 59:582-590.

13. Bottius E, Guanzirolli A, Trape JF, Rogier C, Konate L, Druilhe P: Malaria: even more chronic in nature than previously thought; evidence for subpatent parasitaemia detectable by the polymerase chain reaction. Trans $R$ Soc Trop Med Hyg 1996, 90:15-19.

14. Mayxay M, Pukrittayakamee S, Newton PN, White NJ: Mixed-species malaria infections in humans. Trends Parasitol 2004, 20:233-240

15. Zimmerman PA, Mehlotra RK, Kasehagen LJ, Kazura JW: Why do we need to know more about mixed Plasmodium species infections in humans? Trends Parasitol 2004, 20:440-447.

16. Kasehagen LJ, Mueller I, McNamara DT, Bockarie MJ, Kiniboro B, Rare L, Lorry K, Kastens W, Reeder JC, Kazura JW, et al.: Changing patterns of Plasmodium blood-stage infections in the Wosera region of Papua New Guinea monitored by light microscopy and high throughput PCR diagnosis. Am J Trop Med Hyg 2006 75:588-596.

17. WHO: Roll Back malaria. 2008

18. Randrianarivelojosia M, Raveloson A, Randriamanantena A, Juliano J, Andrianjafy T, Raharimalala LA, Robert V: Lessons learnt from the six decades of chloroquine use (1945-2005) to control malaria in Madagascar. Trans R Soc Trop Med Hyg 2008.

19. Sochantha T, Hewitt S, Nguon C, Okell L, Alexander N, Yeung S, Vannara $H$, Rowland M, Socheat D: Insecticide-treated bednets for the prevention of Plasmodium falciparum malaria in Cambodia: a cluster-randomized trial. Trop Med Int Health 2006, II:II66-1177.

20. Denis MB, Meek SR: Malaria in Cambodia. Southeast Asian J Trop Med Public Health 1992, 23(Suppl 4):23-28.

21. Socheat D, Denis MB, Fandeur T, Zhang Z, Yang H, Xu J, Zhou X, Phompida S, Phetsouvanh R, Lwin S, et al.: Mekong malaria. II. Update of malaria, multi-drug resistance and economic development in the Mekong region of Southeast Asia. Southeast Asian J Trop Med Public Health 2003, 34(Suppl 4): I- 102.

22. CNM: Annual Progress Reports. National Center for Parasitology, Entomology and Malaria Control, Ministry of Health of Cambodia, Phnom Penh, Cambodia 2002.

23. Duval L, Robert V, Csorba G, Hassanin A, Randrianarivelojosia M, Walston J, Nhim T, Goodman SM, Ariey F: Multiple host-switching of Haemosporidia parasites in bats. Malar J 2007, 6:157.

24. Incardona S, Chy S, Chiv L, Nhem S, Sem R, Hewitt S, Doung S, Mercereau-Puijalon $O$, Fandeur $T$ : Large sequence heterogeneity of the small subunit ribosomal RNA gene of Plasmodium ovale in cambodia. Am J Trop Med Hyg 2005, 72:719-724.

25. Escalante AA, Freeland DE, Collins WE, Lal AA: The evolution of primate malaria parasites based on the gene encoding cytochrome $\mathbf{b}$ from the linear mitochondrial genome. Proc Nat Acad Sci USA 1998, 95:8I24-8I29.

26. Coleman RE, Kumpitak C, Ponlawat A, Maneechai N, Phunkitchar V, Rachapaew N, Zollner G, Sattabongkot J: Infectivity of asymptomatic Plasmodium-infected human populations to Anopheles dirus mosquitoes in western Thailand. J Med Entomol 2004, 4I:20I-208.

27. Li J, Gutell RR, Damberger SH, Wirtz RA, Kissinger JC, Rogers MJ, Sattabongkot J, McCutchan TF: Regulation and trafficking of three distinct $18 \mathrm{~S}$ ribosomal RNAs during development of the malaria parasite. J Mol Biol 1997, 269:203-213.

28. Rogers MJ, McConkey GA, Li J, McCutchan TF: The ribosomal DNA loci in Plasmodium falciparum accumulate mutations independently. J Mol Biol I995, 254:88I-89I.

29. Waters AP: The ribosomal RNA genes of Plasmodium. Adv Parasitol 1994, 34:33-79.

30. Kawamoto F, Miyake H, Kaneko O, Kimura M, Nguyen TD, Nguyen TD, Liu Q, Zhou M, Le DD, Kawai S, et al.: Sequence variation in the I 85 rRNA gene, a target for PCR-based malaria diagnosis, in Plasmodium ovale from southern Vietnam. J Clin Microbiol 1996, 34:2287-2289.

31. Liu Q, Zhu S, Mizuno S, Kimura M, Liu P, Isomura S, Wang X, Kawamoto $F$ : Sequence variation in the small-subunit rRNA gene of Plasmodium malariae and prevalence of isolates with the variant sequence in Sichuan, China. J Clin Microbiol 1998, 36:3378-338I.

32. Ballard JW, Whitlock MC: The incomplete natural history of mitochondria. Mol Ecol 2004, I 3:729-744.

33. Conway DJ, Fanello C, Lloyd JM, Al-Joubori BM, Baloch $\mathrm{AH}$ Somanath SD, Roper C, Oduola AM, Mulder B, Povoa MM, et al:: Origin of Plasmodium falciparum malaria is traced by mitochondrial DNA. Mol Biochem Parasitol 2000, II I:163-171.

34. Mclntosh MT, Srivastava R, Vaidya $A B$ : Divergent evolutionary constraints on mitochondrial and nuclear genomes of malaria parasites. Mol Biochem Parasitol 1998, 95:69-80.

35. Perkins SL, Schall JJ: A molecular phylogeny of malarial parasites recovered from cytochrome $b$ gene sequences. J Parasitol 2002, 88:972-978.

36. Vaidya AB, Lashgari MS, Pologe LG, Morrisey J: Structural features of Plasmodium cytochrome $b$ that may underlie susceptibility to 8-aminoquinolines and hydroxynaphthoquinones. Mol Biochem Parasitol 1993, 58:33-42.

37. Feagin JE: The 6-kb element of Plasmodium falciparum encodes mitochondrial cytochrome genes. Mol Biochem Parasitol 1992 , 52:145- 148 .

38. Vaidya $A B$, Akella $R$, Suplick $K$ : Sequences similar to genes for two mitochondrial proteins and portions of ribosomal RNA in tandemly arrayed 6-kilobase-pair DNA of a malarial parasite. Mol Biochem Parasitol 1989, 35:97-107.

39. Price R, Nosten F, Simpson JA, Luxemburger C, Phaipun L, ter Kuile F, van Vugt M, Chongsuphajaisiddhi T, White NJ: Risk factors for gametocyte carriage in uncomplicated falciparum malaria. Am J Trop Med Hyg 1999, 60:1019-1023.

40. Bruce MC, Day KP: Cross-species regulation of Plasmodium parasitemia in semi-immune children from Papua New Guinea. Trends Parasitol 2003, 19:27I-277.

4I. Coura JR, Suarez-Mutis M, Ladeia-Andrade S: A new challenge for malaria control in Brazil: asymptomatic Plasmodium infection-a review. Mem Inst Oswaldo Cruz 2006, I 01 :229-237.

42. Greenwood BM: Control to elimination: implications for malaria research. Trends Parasitol 2008.

Publish with Bio Med Central and every scientist can read your work free of charge

"BioMed Central will be the most significant development for disseminating the results of biomedical research in our lifetime. "

Sir Paul Nurse, Cancer Research UK

Your research papers will be:

- available free of charge to the entire biomedical community

- peer reviewed and published immediately upon acceptance

- cited in PubMed and archived on PubMed Central

- yours - you keep the copyright 